\title{
ENERGY SEPARATION AND BASE PRESSURE IN THE WAKE OF A CIRCULAR CYLINDER
}

\author{
J. R. ACKERMAN", J. P. GOSTELOW ${ }^{*}$, A. RONA ${ }^{\dagger}$ \\ University of Leicester, Leicester, LE1 7RH, UK \\ W. E. CARSCALLEN ${ }^{\ddagger}$ \\ $0_{0}^{2} 0218$ \\ Institute for Aerospace Research, National Research Council of Canada, \\ Ottawa, K1 A 0R6, Canada
}

\begin{abstract}
Turbomachinery flows are inherently unsteady. While this is necessary for the machine's operation it also creates flow inefficiencies. In turbines that have blades with thick trailing edges an important source of unsteady flow is the shedding of vortex streets into the blade wake. The vortex streets causes a separation of the wake flow into areas of high and low energy. This energy separation is non-isentropic and is therefore a source of loss. Vortex shedding also causes the base pressure to fluctuate around a low level.
\end{abstract}

A simplified wake, created by a circular cylinder in compressible cross flow, has been used to model the energy separation and base pressure fluctuation. Time-resolved total temperature and pressure measurements were made six cylinder diameters downstream of the cylinder along with the timeresolved surface pressure. These measurements have then been used to investigate the creation of entropy, and hence loss, in the wake flow and the effect vortex shedding has on the base pressure.

The results showed that entropy creation is associated with vortex shedding and that vortex shedding has a very significant effect on the surface pressure over a large proportion of the cylinder circumference.

\section{Nomenclature}

$C_{b} \quad$ Base pressure coefficient

$C_{o p} \quad$ Pressure coefficient

$C_{p} \quad$ Specific heat at constant pressure $\left(\mathrm{J} \mathrm{kg}^{-1} \mathrm{~K}^{-1}\right)$

$N \quad$ Number of data points used in summation

$P \quad$ Pressure $(\mathrm{Pa})$

$p \quad$ Free stream static pressure $(P a)$

\footnotetext{
Ph.D. Student, email: ja25@le.ac.uk

** Professor, email: jpg7@le.ac.uk

${ }^{\dagger}$ Lecturer, email: ar45@le.ac.uk

† Group Head, email: bill.carscallen@nrc.ca

Copyright $\mathcal{O} 2002$ by the American Institute of

Aeronautics and Astronautics, Inc. All rights reserved.
}

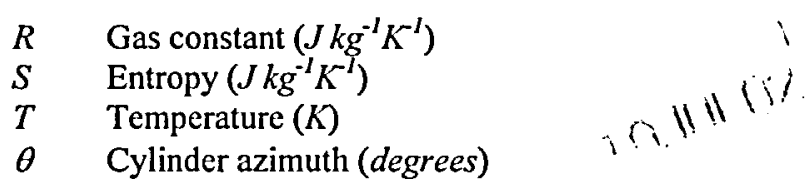

\section{Subscripts}

$\begin{array}{ll}s & \text { Cylinder surface conditions } \\ 01 & \text { Free stream stagnation condition } \\ 02 & \text { Wake stagnation condition } \\ 1 & \text { Upper limit of integration } \\ 2 & \text { Lower limit of integration } \\ 180 & \text { Cylinder trailing edge }\end{array}$

\section{Introduction}

An experimental investigation by Carscallen et al. ${ }^{1}$ into the redistribution of total temperature and pressure in the wake of a turbine stator blade demonstrated the presence of hot and cold spots. The hot and cold spots were indicative of energy separation caused by von Kármán vortex shedding, Kurosaka et $\mathrm{al}^{2}$. The investigation was carried out using a novel total temperature probe, developed at Oxford University by Buttsworth and Jones $^{3}$ for application in transient tunnels and adapted for use in a continuously running facility.

Carscallen et al. ${ }^{1}$ reported the latest in a series of investigations that were instigated by the discovery of an anomalous total temperature distribution in the wake of a highly loaded, low-aspect-ratio (0.6) nozzle guide vane (NGV) (Williamson and Moustapha ${ }^{4}$ ). This led to the commissioning of a transonic planar cascade that modelled the flow using the midspan profile of the nozzle guide vanes at 4.3 times engine size (Carscallen and Oosthuizen ${ }^{5}$ ). Testing on the cascade resulted in a distribution of total temperature similar to the engine rig tests. The effect of the total temperature distribution on the cascade flow was to reduce the time-averaged total temperature in the centre of the blade wake to $12 \mathrm{~K}$ below free stream and to increase it to $8 \mathrm{~K}$ above free stream at the edges of the wake. The understanding of the causes and effects of the total temperature redistribution has evolved mostly through the results of experimental research on the cascade. 
It became apparent that a vortex street was being shed from the thick (6mm diameter) trailing edge over the whole discharge Mach number range of 0.3 to 1.2 . This was confirmed through the use of high frequency response total pressure transducers that were traversed across the wake and through submicrosecond schlieren photography, Carscallen et al. ${ }^{6}$ The schlieren photography indicated that at subsonic Mach numbers the vortex shedding fomed a conventional von Kármán vortex street. However, as the discharge Mach number was increased towards and beyond unity, a number of unconventional vortex shedding modes appeared, classified as couples, doublets, hybrids and leaning von Káman. This change in shedding mode was accompanied by a reduction in the total temperature deficiency in the wake. Figure 1 shows recent schlleren photographs of the wake flow at an exit Mach number of 1.16. It was taker after a minor change was made to the blade geometry to eliminate a design error that had caused the blade to have a slightly bulbous tralling edge.

Turbomachinery blades with thick trailing edges, such as those investigated by Carscallen et al, have a high loss penalty associated with them. This loss penalty is greater than would be expected from a simple backwards facing step and has been quantified by Deych et al. ${ }^{7}$ and Craig and $C^{8}{ }^{8}$. The losses remained unexplained until high speed schlieren photography was applied to cascades, Lawaczek and Heinemann". Vortex shedding was found to be present in the wakes of blades with thick trailing edges, often associated with pressure waves that propagated upstream along the blade surfaces when the local free stream flow was subsonic and appeared at the same frequency as the shed vortices. The unexplained losses were clearly associated with the vortex shedding process.

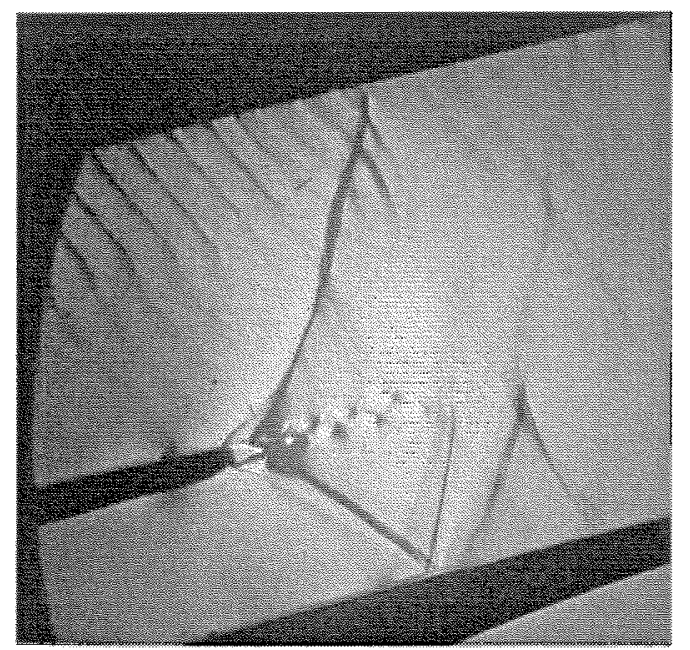

Figure 1. Schlieren Photography of LSTPC Wake Flow at $M=1.16$
In addition to the loss penalty vortex sheding from turbomachinery blades has other, potentially detrimental, thermo-acoustic and mechanical effects. Examples of this are high frequency noise and vibration caused by the fluctuating pressure field in the vortex street and the hot spots created in energy separation causing localised increased heat transfer of downstream blade rows. One of the most important and least understood effects is the redistribution of total temperature in the wake flow. A total temperature distribution, such as that found by Williamson and Moustapha ${ }^{4}$, is a symptom of energy redistribution, usually referred to as the Eckert-Weise ${ }^{10}$ effect, although strictly speaking this term only applies to time-averaged measurements of recovery and wake total temperature. Energy separation is caused by fluctuations of pressure along the curved streamlines of a vortex street, along with minor contributions from viscous forces, causing energy to be transported from the wake side of a vortex to the free stream side, Eckert ${ }^{11}$ and Kurosaka et al. ${ }^{2}$ The extensive work carricd out by Kurosaka et al. ${ }^{2}$ included theoretical and numerical models of energy separation for incompressible flows behind cylinders and, along with the later work by $\mathrm{Ng}$ et al. ${ }^{12}$, experimentally confirmed its presence.

Another detrimental flow phenomenon that is affected by vortex shedding in turbomachinery is base pressure. It has long been realised that turbomachinery blades with thick trailing edges have an area of reduced static pressure around the trailing edge, this reduces efficiency. Cicatelli and Seiverding ${ }^{13}$ conducted an investigation into the effect vortex shedding had on the base region flow. They found that the pressure in this region fluctuated by as much as $8 \%$ of the downstream dymamic head near separation and by $4.8 \%$ in the base region. This would seem to indicate that the instantaneous base pressure could be significantly different from the time-averaged value resulting in blades, if designed using steady state methods, being off condition for much of the vortex shedding cycle.

Carscallen et al. ${ }^{1}$ confirmed that a relationship existed between the energy separation model of Kurosaka and the anomalous total temperature redistribution in the wake low behind the cascade blades. This is despite the thicker boundary layer on the suction surface of the blade which causes the vortices shed from that side to be more loosely rolled up and smeared out when compared to those shed from the pressure side. The results also showed that the energy separation mechanism is nonisentropic, resulting in the localised creation of entropy. Since entropy creation may be considered analogous to loss creation (Denton ${ }^{14}$ ) it is clear that at least some of the unexplained losses in the wake flow are a result of energy separation.

The investigation presented in this paper is a continuation of that carried out by Carscallen et al. ${ }^{1}$ 
Although Kurosaka et al. proved the existence of energy separation in the wake of cylinders in incompressible flow, the investigation did not extend far into the compressible flow regime and no attempt was made to ensemble average the experimental results and to display them in a surface plot similar to that by Carscallen et al $^{1}$. The aim of this investigation was to prove that energy separation does occur in the wake of circular cylinders under compressible flow conditions, to see what effect the vortex shedding had on the base pressure and to gain further insight into the wake flow. As such the results, which are from a preliminary round of testing, will be compared to those of Carscallen et al. ${ }^{1}$

The investigation was conducted by traversing high frequency response total temperature and pressure probes behind a circular cylinder in cross flow under compressible conditions. Once again use was made of the total temperature probe developed at Oxford University, although a different method of operation had to be developed, alongside a Kulite XCQ-062-25D ultraminiature pressure transducer, to make the traverse.

Unlike the case of a turbine blade the boundary layers on either side of the circular cylinder were symmetrical and sufficiently thin so as to not smear the vortices. The results of the wake traverse would also need to be handled in an automated manner due to the nine-fold increase in the number of data points acquired.

In addition to the wake traverses, surface pressure readings from around the cylinder were also taken in an effort to increase understanding of the relationship between vortex shedding and the base pressure of cylinders and turbine blades.

\section{Facility and Instrumentation For Circular Cvlinder Testing}

A 1.5 metre trisonic blowdown wind tunnel with a two-dimensional (2-D) flow inset fitted in the working section was used for this investigation. The schematic of the 2-D insert is shown in figure 2.

The test section of the 2-D insert measured $0.381 \mathrm{~m}$ $\times 1.524 \mathrm{~m} \times 3.581 \mathrm{~m}\left(15^{\prime \prime} \times 60^{\prime \prime} \times 141 "\right)$ with the inlet nozzle taking up a further $1.905 \mathrm{~m}$ (75"). The air supply consisted of three $1.430 \mathrm{~m}^{3}$ tanks that could be pressurised up to $2.13 \mathrm{MPa}(21 \mathrm{~atm})$. In this mode the wind tunnel had a discharge Mach number range of 0.1 to 0.9 and was run a constant Reynolds number. The operating Reynolds number range and run time were dependent on Mach number and was set by adjusting the total and static pressure. Blowdown operation resulted in the free stream total temperature dropping over the course of each run as the air in the supply tanks expanded. The flow conditions for the test are given in table 1 .

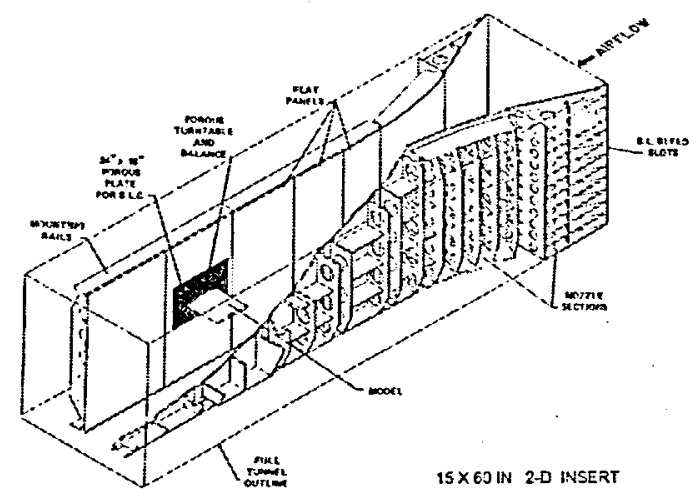

Figure 2. 2-D Test Section For The Trisonic Blowdown Wind Tunnel

\begin{tabular}{|lr|l|}
\hline $\mathrm{M}$ & & 0.6 \\
\hline $\mathrm{Po}$ & $\mathrm{kPa}(\mathrm{PSIA})$ & $156.8(22.74)$ \\
\hline $\mathrm{P}$ & $\mathrm{kPa}(\mathrm{PSIA})$ & $122.9(17.83)$ \\
\hline $\mathrm{Q}$ & $\mathrm{kPa}(\mathrm{PSIA})$ & $31.0(4.492)$ \\
\hline $\mathrm{Po}-\mathrm{P}$ & $\mathrm{kPa}(\mathrm{PSIA})$ & $33.85(4.91)$ \\
\hline $\mathrm{Re} / \mathrm{ft}$ & $\mathrm{m}^{-1}\left(\mathrm{ft}^{-1}\right)$ & $1.80 \times 10^{7}\left(5.50 \times 10^{6}\right)$ \\
\hline $\mathrm{Re}$ & & $6.875 \times 10^{5}$ \\
\hline
\end{tabular}

Table 1. Test Conditions

The model was mounted $2.388 \mathrm{~m}$ (94") downstream of the end of the nozzle on reinforced mounts in the threecomponent balance. Due to the method of reinforcement it was impossible to take measurements of the forces acting on the cylinder from the balance. Boundary layer control was supplied using ejectoraugmented sidewall suction through $0.602 \mathrm{~m} \times 0.452 \mathrm{~m}$ $\left(24 " \times 18^{\prime \prime}\right)$ porous plates, see figure 2 . The balance could be rotated through a range of $\pm 55^{\circ}$ at a rate of $15^{\circ}$ per second.

The model was an aluminium circular cylinder with a diameter of $37.26 \mathrm{~mm}$ (1.467') and a span of $381 \mathrm{~mm}$ (15"). A single Kulite XCQ-062-25D ultraminiature pressure transducer was mounted so that the B-screen, which covered the pressure sensitive diaphragm, was flush with the cylinder surface at midspan.

The wake probe used for the traverse downstream of the cylinder consisted of the total temperature probe developed at Oxford University alongside a tube mounted Kulite XCQ-062-25D ultraminiature pressure transducer. These were mounted in a green glass holder that was attached to the end of a stainless steel tube. The Kulite pressure transducer was mounted so that its face was looking directly into the flow, allowing it to measure the total pressure. The probes were mounted so that their tips were all level and aligned along the horizontal spanwise axis of the wind tunnel. Since the vortex shedding was assumed to be two-dimensional, 
mouning the probes in this way ensured that they would all see the vortex passing events simulaneously.

The sting was mounted onto the wake traverse by way of a triangulated support. The sting and support were designed so that the probe tips would be six cylinder diameters, $223.6 \mathrm{~mm}$ (22.14"), downstream of the model's leeward most point as in figure 3 .

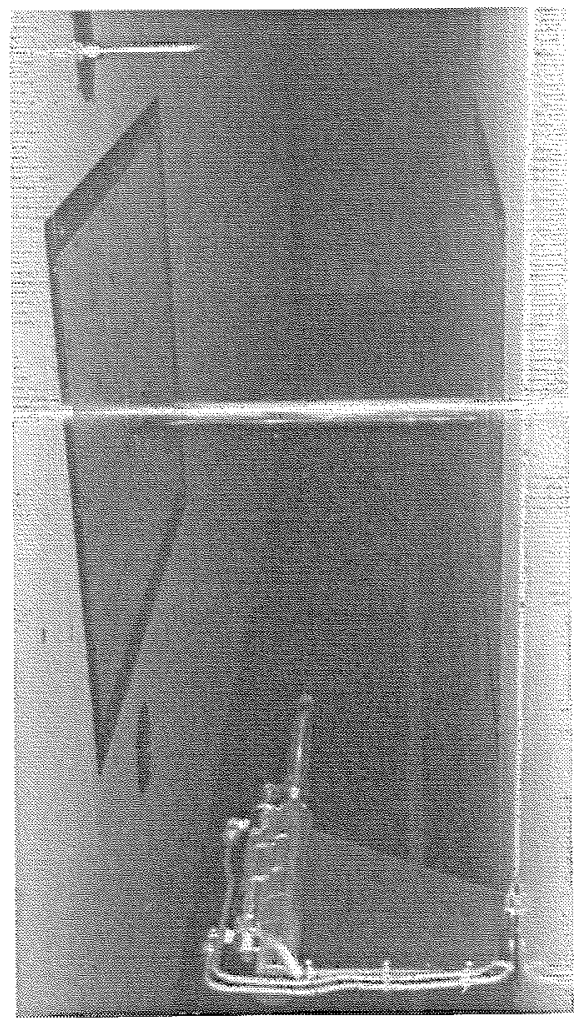

Figure 3. Cylinder and Wake Probe Mounted in Wind Tunnel

Measurement of total temperature was taken using the probe developed at Oxford University by Buttsworth and Jones ${ }^{3}$. The probe actually consists of two probes each consisting of a $3 \mathrm{~mm}$ diameter rod of fused quartz, one end of which is hemispherical. The hemispherical tips of both probes are painted with a platinum thin film resistance thermometer. Leads of gold paste are painted along the sides from the ends of the platinum thin films to the end of the probe to act as contacts for wiring.

Since Buttsworth and Jones ${ }^{3}$ have described the measuring technique for the total temperature probes in detal, only a brief description accompanied with an explanation of the peculiarities of the operation for this particular test will be included here. The heat transfer between the quartz and the flow is govemed by the heat transfer coefficient, the surface temperature of the quartz and total temperature of the flow at the stagnation point. The thin film gauges were run in constant cuirent mode so that the surface temperature of the quartz could be deduced from the voltage drop across the gauge. A high frequency heat transfer signal was generated from the gauge voltage via Oldfield et al's ${ }^{\text {is }}$ heat transfer analog. Since both probes were nominally identical they could be assumed to have the same heat transfer coefficient. Thus by heating one of the probes with a small internal heater prior to each measurement so that the two probes had different surface temperatures it was possible to simultaneously solve the heat transfer ecuation for both probes to calculate the flow total temperature. Corrections were applied for surface curvature effects and lateral conductions as described by Butsworth and Jones ${ }^{3}$. Error analysis carried out by Buttsworth and Jones showed that a measurement accuracy of $\pm 3 \mathrm{~K}$ could be expected from the probe. The frequency response of the thin film probes was limited by the conditioning electronics of the heat transfer analog to $87 \mathrm{kHz}$.

The total temperature probe was originally designed for use in transient wind tunnels. Since run times of up to two minutes were expected a novel way of using the probe had to be developed. The solution involved two complementary methods. The first method was to use an open-ended sheath that moved forward over the probe head during heating providing an enclosure of stagnation flow. The second method involved closing the wind tumel control valve and traversing the probe to $120 \mathrm{~mm}$ below the tunnel centre line. By doing this the free strean Mach number was reduced to 0.1 to 0.15 and the probe was moved out of the fuctuating wake flow. In this way the probe could be heated in steady conditions with very little flow passing over it. Once the heated probe had reached $393 \mathrm{~K}$ the heater was switched off, the control valve opened, the probe traversed into position and data acquisition started. After 0.2 seconds of data collection the sheath was withdrawn, opening the probe to the flow. Data collection then continued for a further 1.8 seconds.

The traverse across the wake was conducted at $y$ values from $120 \mathrm{~mm}$ above the wake to $132 \mathrm{~mm}$ below the wake in steps of $3 \mathrm{~mm}$. This took five blowdowns, each with 15 steps. The first step of each blowdown repeated the last step of the previous to ensure repeatability between the runs. Simultaneous to each wake measurement a reading was taken from the Kulite pressure transducer in the cyllinder to act as a phase reference. For this purpose the cylinder was rotated so that the cylinder transducer was positioned $120^{\circ}$ from the leading edge.

Surface pressure measurements were taken at $5^{\circ}$ steps from $10^{\circ}$ below the leading edge through to $10^{\circ}$ below the trailing edge. Data were taken for two seconds at each step. The traverse was taken over two blowdowns, the first of which traversed the cylinder from $10^{\circ}$ below the leading edge round to $100^{\circ}$ above it while the 
second went from the $80^{\circ}$ to the $190^{\circ}$ locations. Alongside each surface pressure reading a measurement was taken from the wake probe pressure transducer that was to act as a phase reference. For this purpose the wake probe was traversed to $30 \mathrm{~mm}$ above the wake.

Both phase reference positions were chosen because pressure measurements at these locations had very strong signals that were dominated by the fundamental frequency of the vortex shedding.

Unfortunately due to high frequency noise the total temperature measurements had a poor signal to noise ratio. The poor signal to noise ratio is demonstrated by the raw heat transfer trace from the heated thin film in figure 4 . It was later discovered that this was due to auxiliary equipment that activated intermittently during the run.

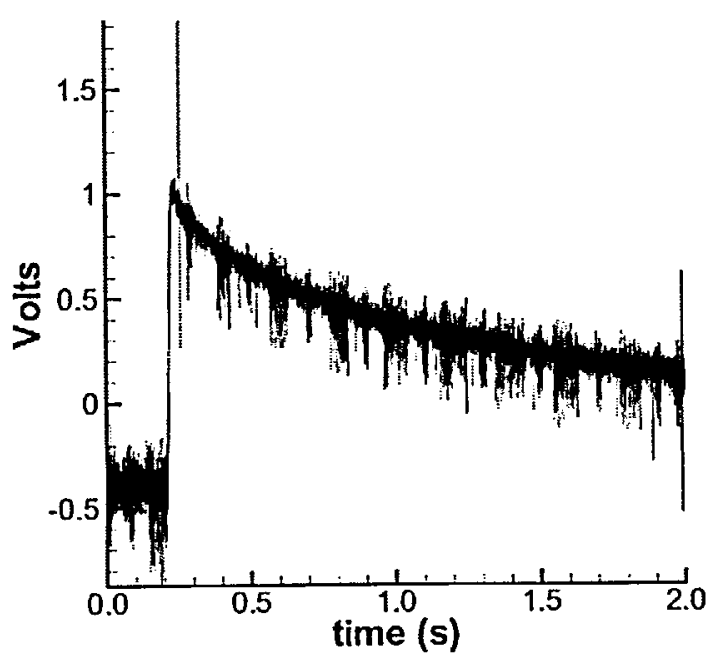

Figure 4. Raw Heat Transfer Signal From Heated Total Temperature Probe

The signals were subjected to a $40 \mathrm{kHz}$ low-pass anti-aliasing filter before being recorded directly onto PC through National Instruments data acquisition cards at a sample rate of $100 \mathrm{kHz}$.

Calibration procedures were applied to the data resulting in the production of total temperature and pressure signals in physical units. To build up a picture of the effect energy separation had on the wake flow and to remove the high level of noise, ensemble averaging was carried out on the data using the phase reference signals, after appropriate filtering to remove noise and harmonic content. The ensembles comprised of 64 blocks of eight cycles. The large number of blocks was necessary to remove the noise from the signals; unfortunately it also resulted in removing much of the harmonic content resulting in almost sinusoidal signals (Figure 5). To ensure that none of the data taken prior to the sheath being withdrawn or while the flow was establishing itself, were included in the ensemble averaging the first 0.3 seconds of data of each record were discarded.
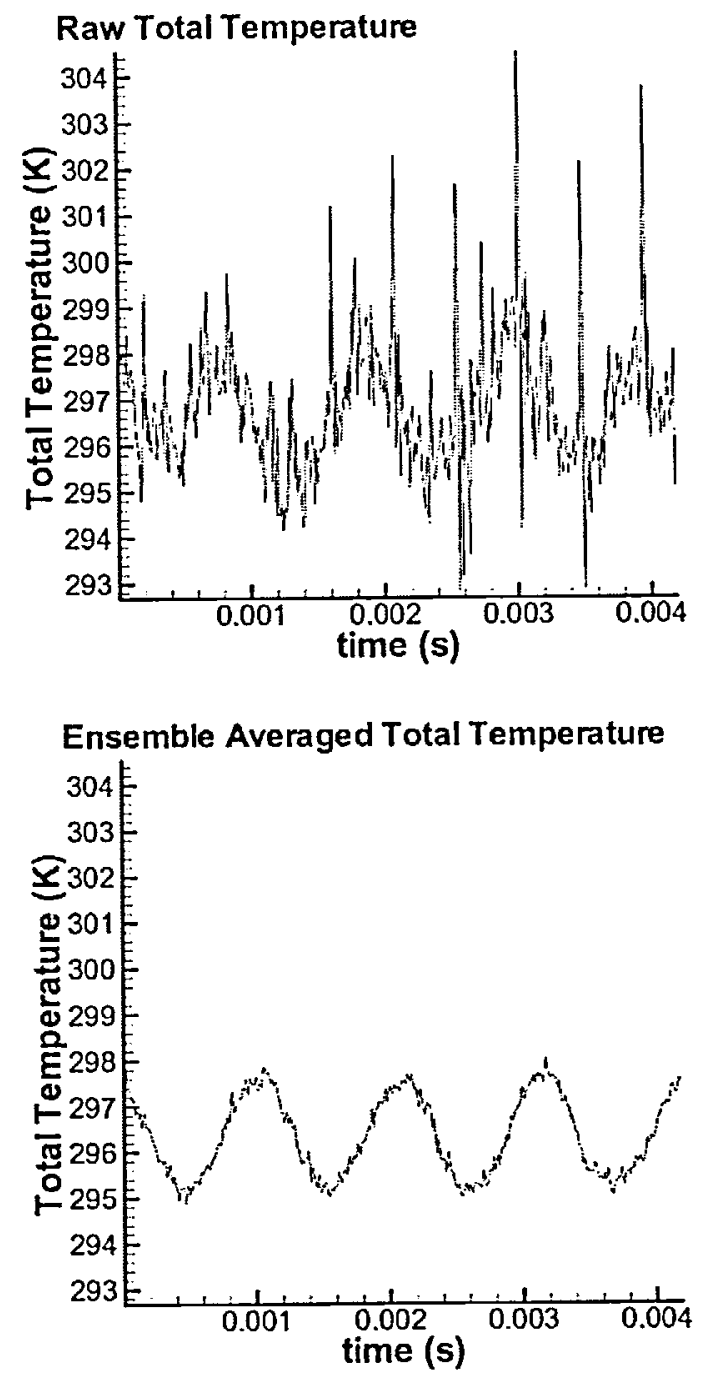

Figure 5. Non-Averaged and Ensemble Averaged Total Temperature Data

The use of a common phase reference transducer for all the wake data and a similar common phase reference for the cylinder surface data enabled the data to be combined into the contour plots in figures $6 \mathrm{a}, 7 \mathrm{a}, 8 \mathrm{a}$ and 9 a.

\section{$\underline{\text { Results and Discussion }}$}

\section{Phase 1}

Contour plots are presented for 419 readings, or $4.19 \mathrm{~ms}$, of phase averaged total temperature and pressure data in figures $6 \mathrm{a}$ and $7 \mathrm{a}$. The time sequence for these data has been reversed so as to more closely relate to the Lagrangian views of the vortical flow obtained from schlieren photography, computational simulations and the results of Carscallen et al. ${ }^{\text {C Contour }}$ 


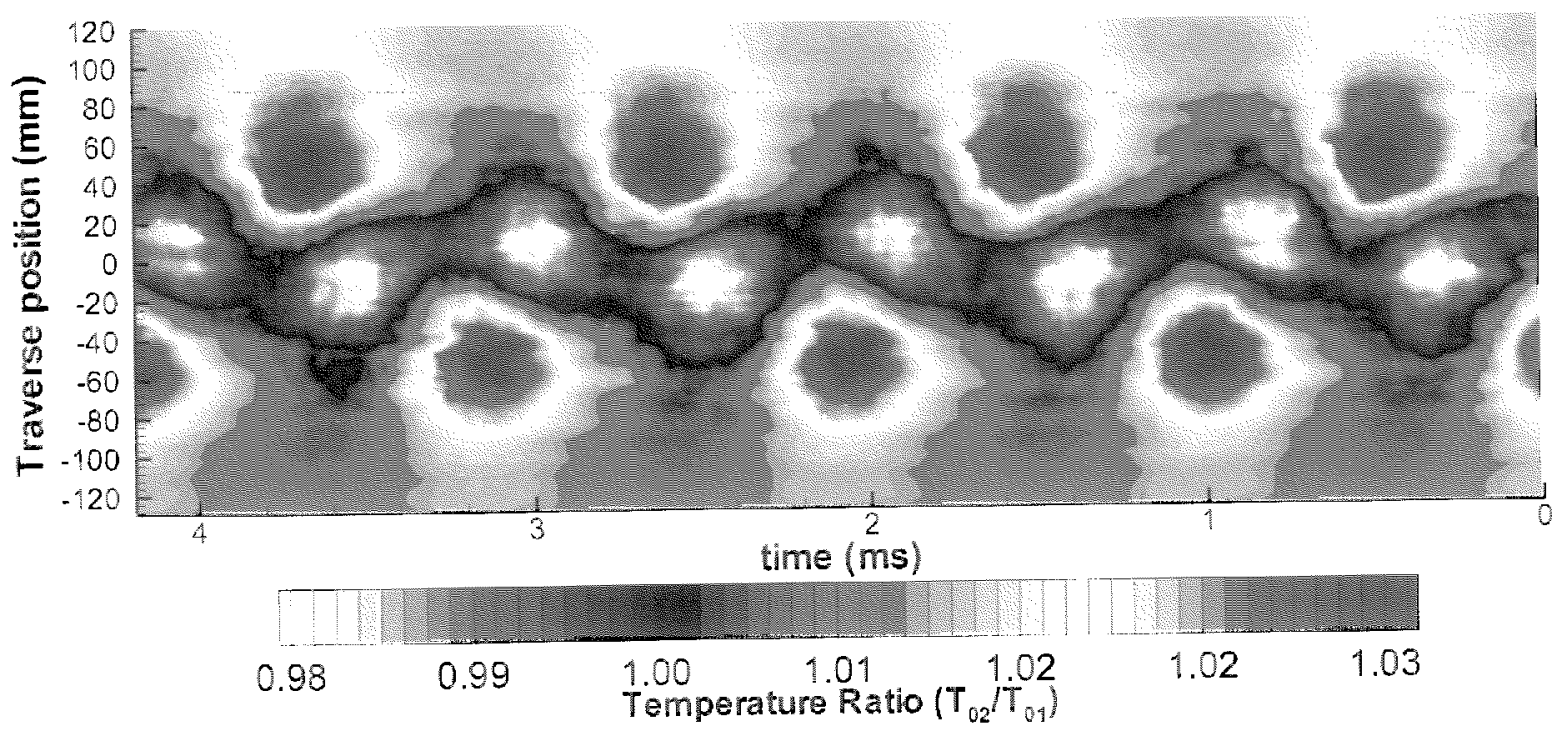

Figure 6a. Total Temperature Fluctuations Behind a Circular Cylinder

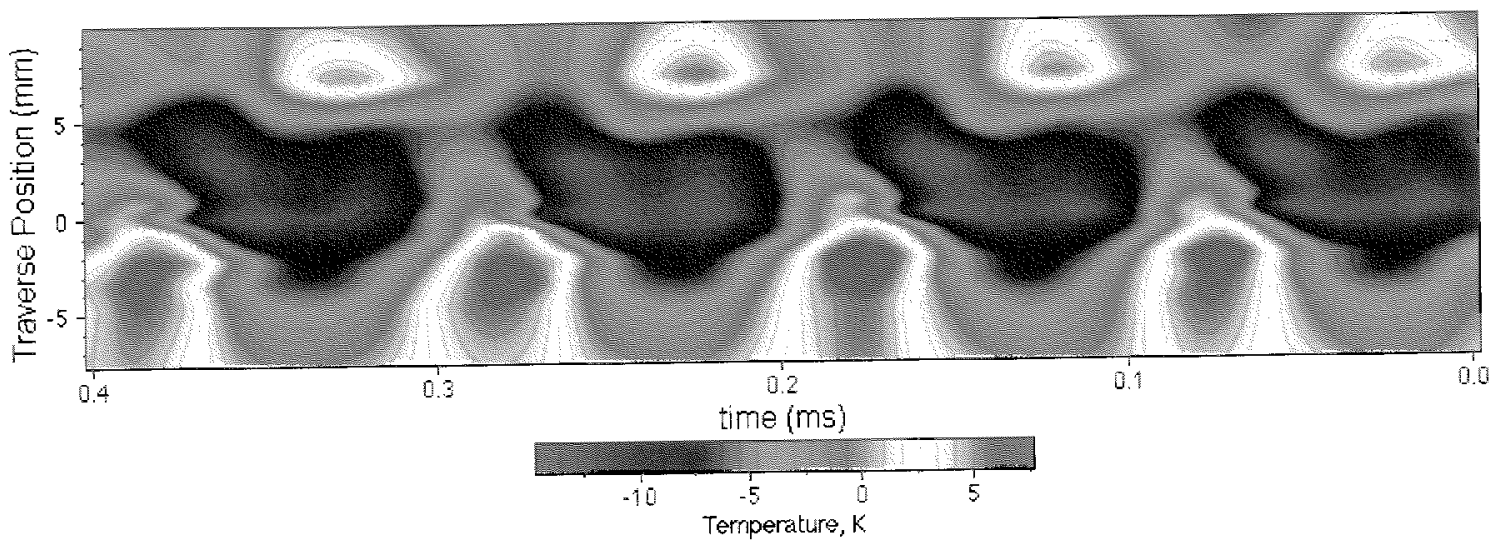

Figure 6b. Total Temperature Fluctuations Behind a Turbine Blade

plots of the results from Carscallen et al. ${ }^{1}$ are reproduced in figures $6 \mathrm{~b}, 7 \mathrm{~b}$ and $8 \mathrm{~b}$ for comparison.

Unfortunately, due to the nature of the wind tumnels used for the two investigations, the data are presented differently. The planar cascade used in Carscallen et al's study was an inlet facility that had a constant free stream total temperature. Thus the results from that investigation may be shown in physical units. The blowdown facility used for the current investigation has a constantly dropping free stream total temperature. Thus the results have to be presented as a ratio of wake total temperature to free stream total temperature. For consistency the same approach has been taken with the wake total pressure.

Figure 6a clearly shows the presence of hot spots at the edge of the cylinder wake and cold spots, appearing at its centre. The hot spots rise to maximum of $103.6 \%$ of the free stream total temperature and the cold spots fall to a minimum of $97.7 \%$ of free stream total temperature. This represents, assuming a free stream total temperature of $293 \mathrm{~K}$, a maximum total temperature rise of $10.5 \mathrm{~K}$ in the hot spots at the edge of the wake and a maximum drop of $6.7 \mathrm{~K}$ in the cold spots. When compared to the results from the cascade testing by Carscallen et al. ${ }^{\prime}$ in figure $6 b$ there is a similarity. Both contour plots show clear hot spots at the edges of the wake along with cold spots in the centre. However the cascade results seem to exhibit an almost staggered appearance. This is probably due to the unsymmetrical nature of the vortex shedding from the cascade. It is interesting to note that the values for the maximum and minimum total temperatures in the wake in both cases were similar despite the cylinder wake being about ten times wider that that of the cascade. In the case of the pressure surface side of the cascade wake the total temperature could reach $16 \mathrm{~K}$ above the free stream value and go down to $8 \mathrm{~K}$ below while on the suction surface the total temperature could go up to $8 \mathrm{~K}$ above free stream.

There are also strong similarities between the total pressure plots for the cylinder work and Carscallen et al's cascade work, figures $7 \mathrm{a}$ and $7 \mathrm{~b}$. In both cases there are pronounced spots of reduced total pressure in the wake centre, in the case of the cylinder going. 


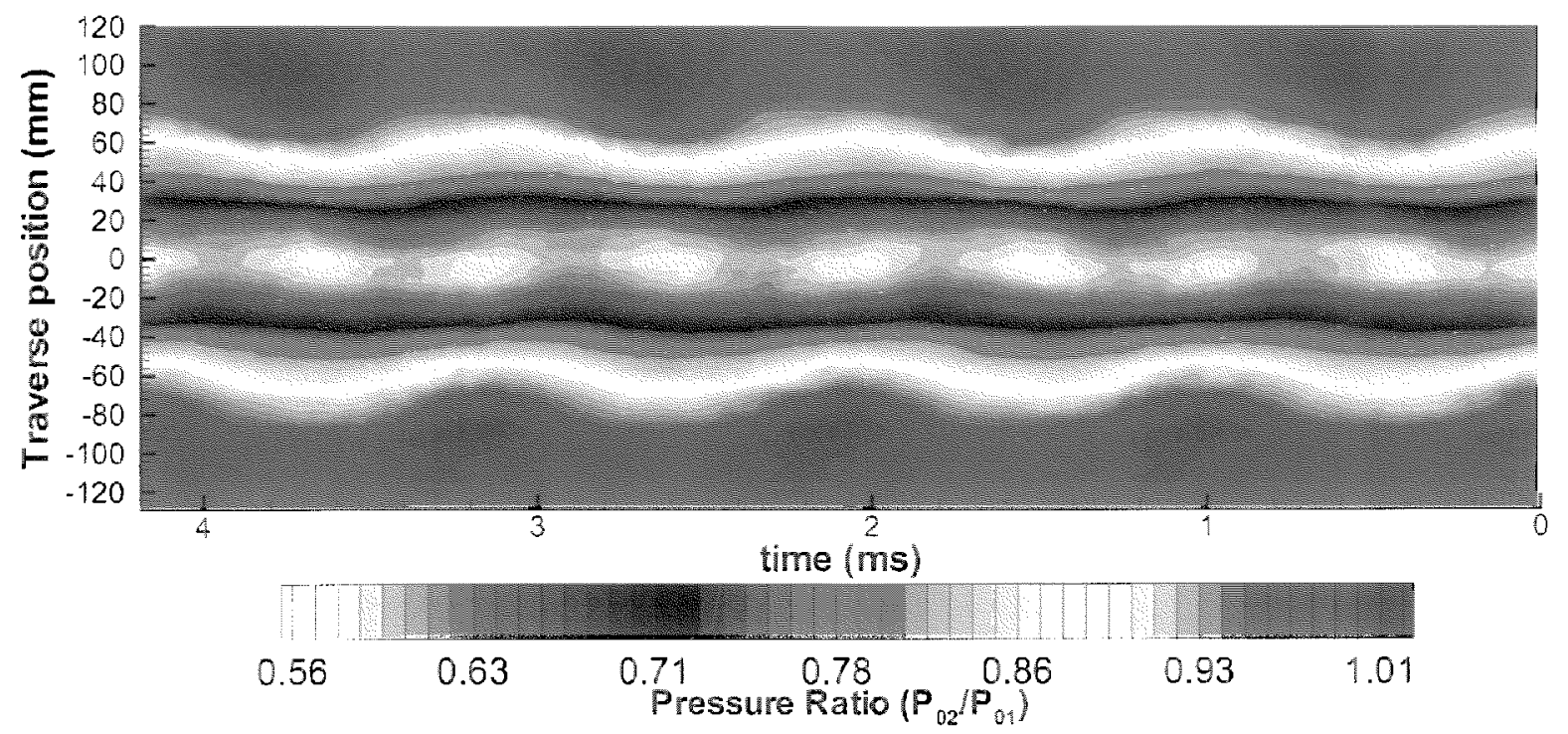

Figure 7a. Total Pressure Fluctuations Behind a Circular Cylinder

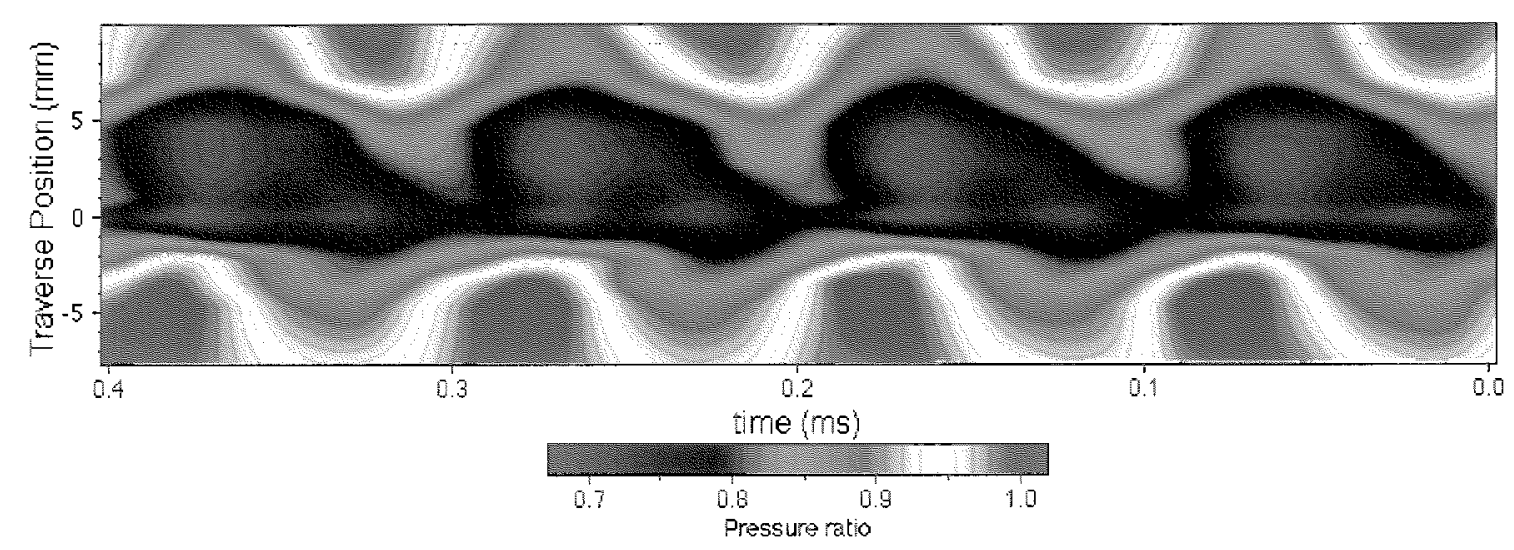

Figure 7b. Total Pressure Fluctuations Behind a Turbine Blade

down as low as $58 \%$ of free stream total pressure and in that of the cascade going down to below $70 \%$ of the free stream value. Also of note, in both cases the areas of decreased total pressure appear more smeared out and tend to encroach into the freestream along the edges of the wake.

The results of the time-resolved total temperature and pressure in the wake of the circular cylinder in compressible flow support the observations of Carscallen et al. ${ }^{1}$ for the flow behind a turbine blade and extend those of Kurosaka et al. ${ }^{2}$ into the compressible flow regime. It also demonstrates the adaptability of the total temperature probe developed by Buttsworth and Jones ${ }^{3}$ and proves the usefulness of its application alongside a total pressure probe.

To investigate more closely loss production in vortex streets behind circular cylinders and to enable further comparison with the results of Carscallen et al. ${ }^{1}$ the total temperature and pressure results were used to calculate the creation of entropy in a vortex street. The relationship for entropy creation in a perfect gas in terms of total temperature and pressure is:

$$
s_{2}-s_{1}=c_{p} \ln \left(T_{02} / T_{01}\right)-R \ln \left(P_{02} / P_{01}\right)
$$

Using the above relationship along with the total temperature and pressure results the entropy created in the wake of the circular cylinder was calculated, figure 8a. The entropy is created when expansions and compressions in the wake depart from isentropic flow. The expansions and compressions in flow show up as fluctuations in total pressure and so can be seen in figure 7a. The compressions and expansions cause the total temperature to change but this lags the total pressure. When the total temperature cannot match the expansions and compressions, as is the case in the results presented here, irreversibilities are created causing entropy production. 


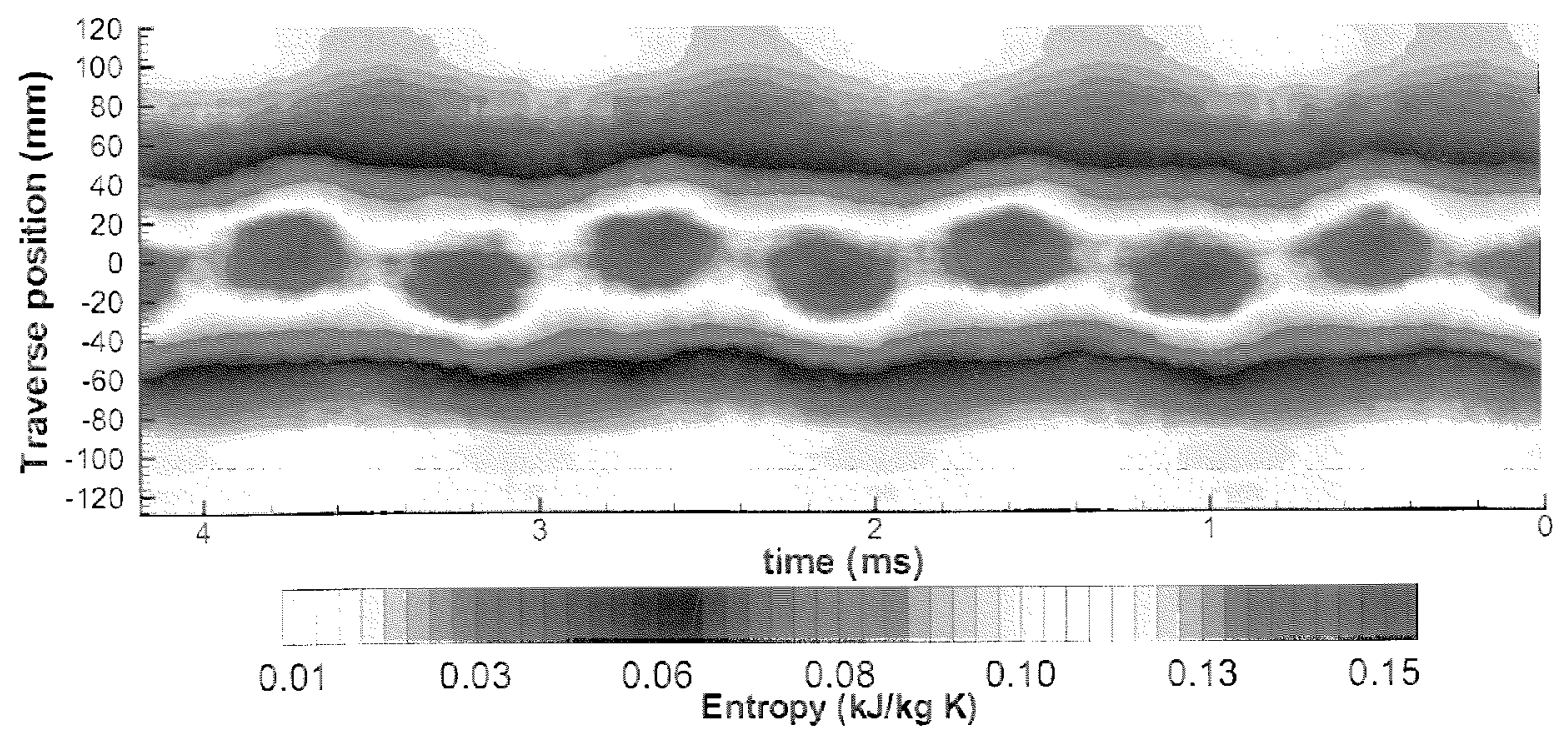

Figure 8a. Entropy Creation Behind a Circular Cylinder

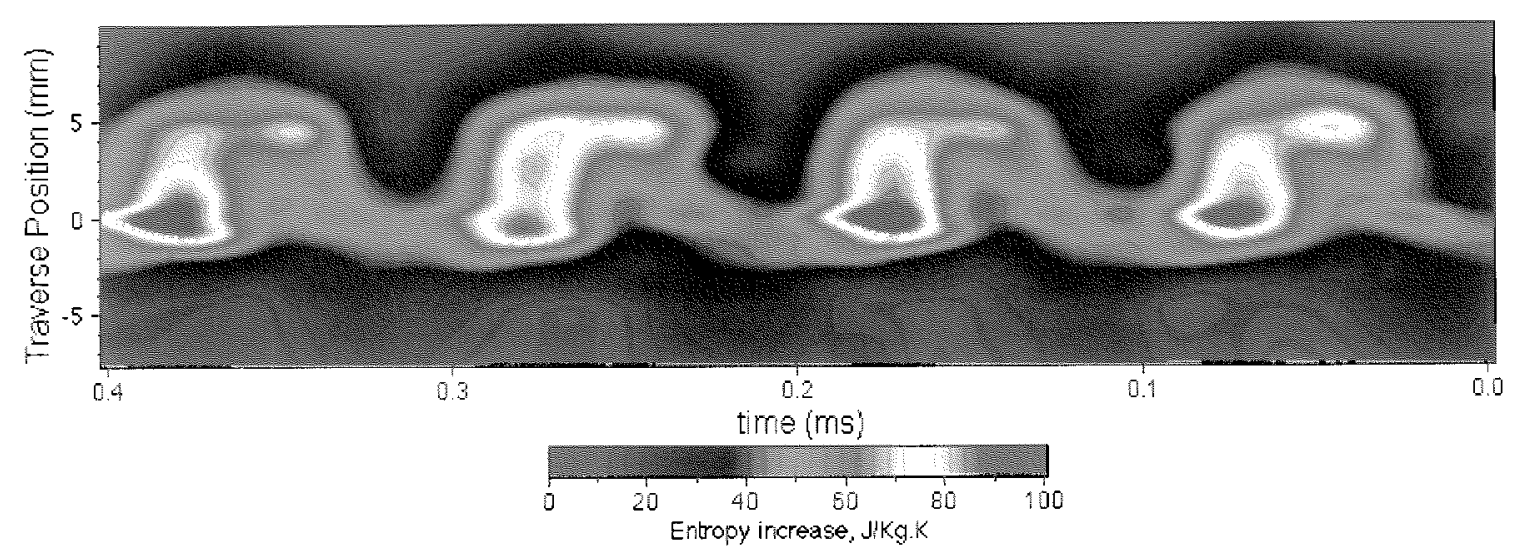

Figure 8b. Entropy Creation Behind a Turbine Blade

When compared with the results from Carscallen et al, figure $8 \mathrm{~b}$. This however is misleading. In both cases the entropy maxima are located at the total pressure minima. It seems that this is due to the total temperature minima being spatially located further out in the wake. The serpentine shape of the entropy contour from the cascade tests is largely due to mismatching between the trailing edge boundary layers and their influence on the vortex street. Since the boundary layers at separation on the cylinder are matched a more symmetrical behaviour would be expected.

\section{Phase 2}

A contour plot is presented for 419 readings, or $4.19 \mathrm{~ms}$, of the variation of phase averaged pressure coefficient data around half of the cylinder's surface in figure 9. The pressure coefficient is defined as:

$$
C_{o p}=\frac{P_{s}-p}{P_{01}-p}
$$

It is clear from figure 9 that there are periodic pressure fluctuations about the leeward side of the cylinder. The areas of high, or low, pressure seem to originate at around the $90^{\circ}-100^{\circ}$ location and move both towards the front and rear of the eylinder with time. This is due to two interconnected mechanisms. As a vortex separates from the cylinder surface it causes an area of low pressure to form. Since the separation moves across the surface of the cylinder this causes the area of low pressure to sweep towards the rear of the cylinder. At the same time the shear layer from the other side of the wake is swinging across to the side of the wake that is shedding the vortex causing an area of high pressure to sweep towards the rear on that side. The areas of low pressure moving forward are due to pressure waves moving forward across the cylinder surface. These pressure waves appear with every vortex shedding event and have been observed on a number of occasions in convergent turbine cascades (Lawaczek and Heinemann ${ }^{9}$, Cicatelli and Sieverding ${ }^{13}$ and Carscallen et al ${ }^{16}$ ).

The significance that the vortex shedding and the limits of integration have on the time-resolved and time-averaged base pressure are shown by the size of 


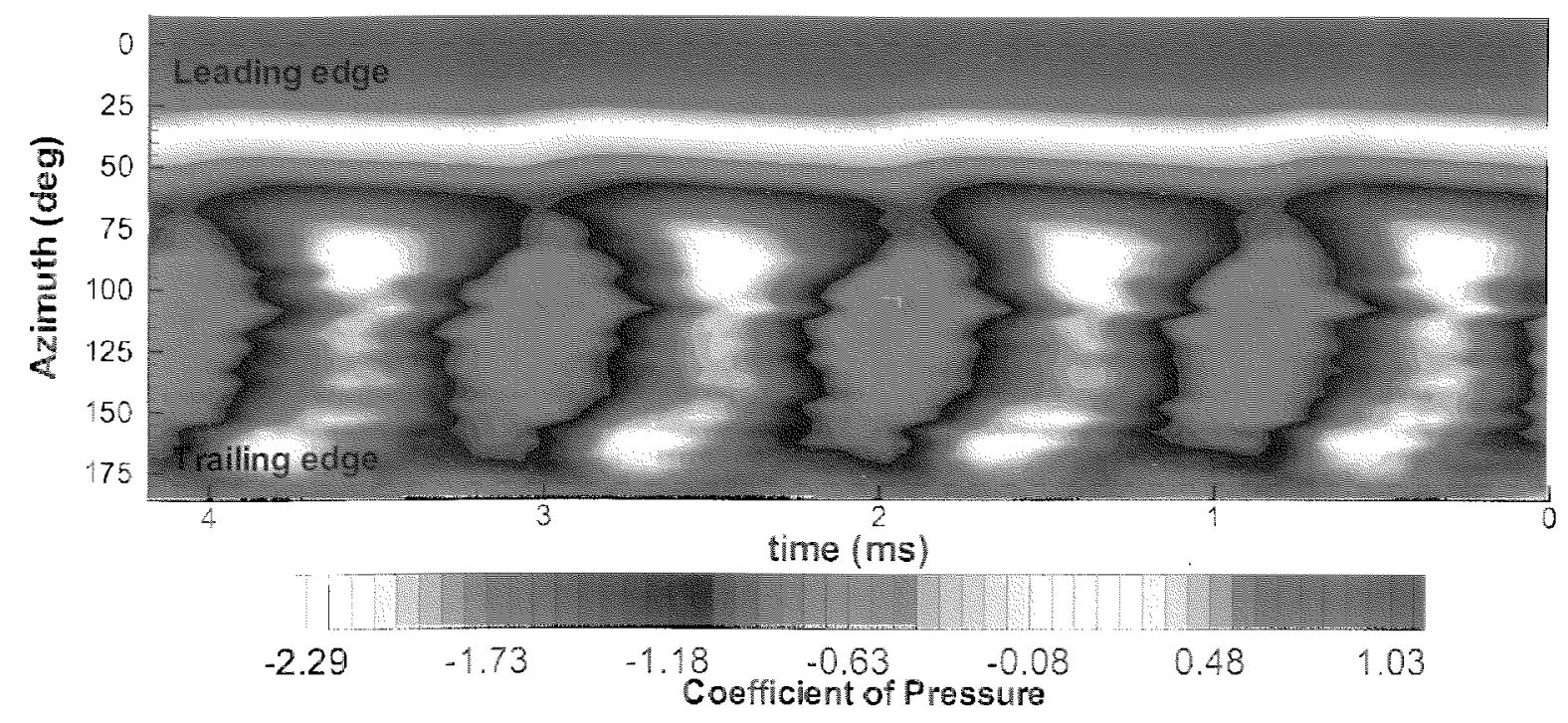

Figure 9. Cylinder Surface Pressure Coefficient

the fluctuations in pressure coefficient about the leeward side of the cylinder in figure 9 . The amplitude of the fluctuations in the time-resolved pressure coefficient decreases towards the windward side of the cylinder while the time-averaged value increases. The fluctuations in the time-resolved base pressure coefficient would then decrease as the integration limits moved further apart while the timeaveraged value would increase.

Unfortunately, because data from only one half of the cylinder surface, it was not possible to directly calculate the time-resolved base pressure coefficient. However the time-averaged base pressure coefficient may be calculated. This is because, assuming symmetry, the averaged pressure between the upper limit of integration and the tralling edge is equal to that between the lower limit and the trailing edge so long as the limits are equidistant from the trailing edge. Thus the integration of the pressure coefficient between the upper limit and the trailing edge is equal to the integration of the coefficient of pressure between the two limits and so is equal to the base pressure, i.e.

$$
\begin{aligned}
& C_{b}=\frac{1}{2 \Delta \theta} \int_{\theta_{0}}^{\theta_{2}} C_{o p} d \theta=\frac{1}{N} \sum_{n=\theta_{3}}^{\theta_{2}} C_{o n} \\
& C_{b}=\frac{1}{2 N} 2 \sum_{n=\theta_{1}}^{\theta_{i s p}} C_{o p}=\frac{1}{N} \sum_{n=\theta_{1}}^{\theta_{i n p}} C_{o p}
\end{aligned}
$$

Where $\theta_{1}$ and $O_{2}$ are the equally spaced limits of integration ether side of the trailing edge of the cylinder, $\theta_{1 \%}$ is located the tralling edge, $\Delta \theta$ is the angle between $\theta_{i, n}$ and $\theta_{1}$ and $N$ is the number of data points over which the summation was made. The value of $\theta_{1}$ or $\theta_{2}$ closest to the leading edge were $100^{\circ}$ back from it. This point was chosen because it is the time-averaged separation point.

The data shown in figure 10 support the above statement showing that the base pressure coefficient becomes less negative as $2 \Delta \theta$ increases. Figure 10 also shows a change in the way that the coefficient of base pressure increases as $2 \Delta \theta$ increases beyond about $30^{\circ}$. This is because the large pressure fluctuations produced further towards the windward side of the cylinder quickly hide the very low values of pressure coefficient that are found within $10^{\circ}$ of the trailing edge.

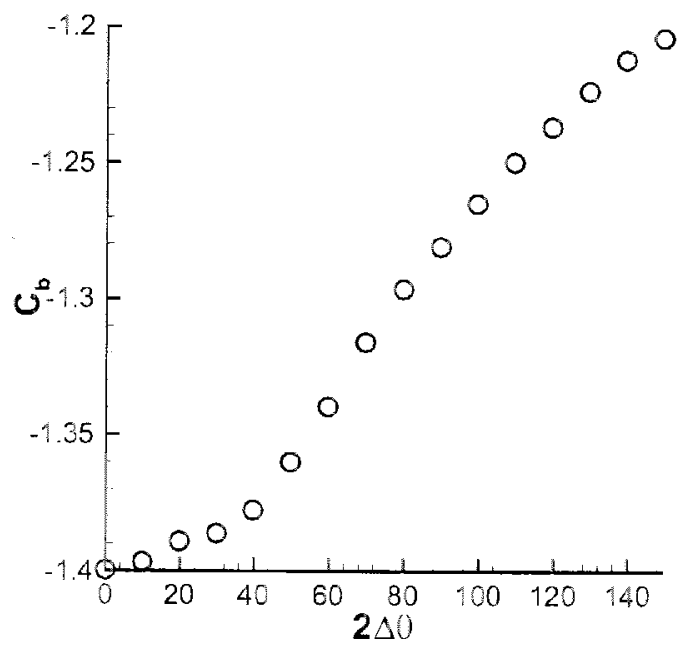

Figure 10. Time-averaged Coefficient of Base Pressure

\section{Conclusion}

Strong energy separation is shown to be present in the wake flow of a circular cylinder in compressible cross 
flow. Hot spots were measured at the edges of the wake while cold regions were measured in the wake core. Corresponding areas of high and low pressure accompanied these hot areas and cold spots. The process is non-isentropic and so is a source of entropy creation. Fluctuations in entropy creation were calculated from the total temperature and pressure measurements.

The results support the findings of Carscallen et al. ${ }^{1}$ showing a marked similarity to their measurements of total temperature and pressure in the wake of a turbine blade with a thick trailing edge. They also display the versatility of the total temperature probes developed by Buttsworth and Jones ${ }^{3}$ that were used both in this investigation and in that of Carscallen et al.

Phase 2 of the investigation also showed the presence of very strong pressure fluctuations over the leeward side of the cylinder caused by the vortex shedding. It has been shown that this will have a significant effect on any base pressure measurement.

\section{Acknowledgments}

A research grant from the British EPSRC is gratefully acknowledged. The authors are indebted to $\mathrm{J}$. Templin of the National Research Council of Canada for the use of the U-66 wind tunnel and work shop facilities. In addition thanks is due to Prof. T.V. Jones, Dr. S.I. Hogg, Mr. P. Hunt and Dr. E. Hanff.

\section{$\underline{\text { References }}$}

1. Carscallen, W.E., Currie, T.C., Hogg, S.I., and Gostelow, J.P., 1999, "Measurement and computation of energy separation in the vortical wake flow of a turbine nozzle cascade," ASME Journal of Turbomachinery 121, No.4., pp 703708.

2. Kurosaka, M., Gertz, J.B., Graham, J.E., Goodman, J.R., Sundram, P., Riner, W.C., Kuroda, H., and Hankey, W.L., 1987, "Energy separation in a vortex street," Journal of Fluid Mechanics 178, pp. 1-29.

3. Buttsworth, D.R., and Jones, T.V., 1996, "A fastresponse total temperature probe for unsteady compressible flows," ASME Journal of Engineering for Gas Turbines and Power 120, pp. 694-701.

4. Williamson, R. G., and Moustapha, S.H., 1986, "Annular cascade testing of turbine nozzles at high exit mach numbers," ASME Joumal of Fluids Engineering 108, pp. 313-320
5. Carscallen, W.E., and Oosthuizen, P.H., 1989, "The effect of secondary flows on the redistribution of the total temperature field downstream of a stationary turbine cascade," AGARD-CP-469.

6. Carscallen, W.E., Fleige, H.U., and Gostelow, J.P., 1996, "Transonic turbine vane wake flows," ASME Paper No. 96-GT-419.

7. Deych, M.E., Fillipov, G.A., and Lazerev, L. Y. A., 1965, "Atlas of axial turbine cascade characteristics," Mash. Publishing house, Moscow.

8. Craig, H.R.M. and Cox, H.J.A., 1971, "Performance estimation of axial flow turbines," Proc. I. Mech.E. Vol. 185, 32/71.

9. Lawaczeck, O., and Heinemann. H. J.,1976,"Von Kármán streets in the wakes of subsonic and transonic cascades," AGARD CP 177.

10. Eckert, E.R.T., and Weise, W., 1943, "Messungen der Temperaturerteilung auf der ober Flache Schnell Angestromter Unbeheizter Korper," Forshg. Ing. Wesen. 13, pp. 246-254.

11. Eckert, E.R.T., 1984, "Experiments on energy separation in fluid streams," journal of mechanical engineering 106, No.10, pp. 58-65.

12. Ng, W.F., Chakroun, W.m., and Kurosaka, M., 1990, "Time-resolved measurements of total temperature and pressure in the vortex street behind a cylinder," Physics of Fluids A 2, No.6, pp. 971-978.

13. Cicatelli, G., and Sieverding, C. H., 1996, "The effect of vortex shedding on the unsteady pressure distribution around the trailing edge of a turbine blade," ASME paper 96-GT-359.

14. Denton, J. D., 1993, "Loss mechanisms in turbomachines", Journal of Turbomachinery 115 , Oct, pp 621-656.

15. Oldfield, M.L.G., Burd, H.J., and Doe, N.G., 1982, "Design of wide-bandwidth analogue circuits for heat transfer instrumentation in transient tunnels," $16^{\text {th }}$ Symposium of Intemational Centre for Heat and Mass Transfer, Hemisphere Publishing, pp. 233-257.

16. Carscallen, W.E., and Gostelow, J.P., 1994, "Observations of vortex shedding in the wake from transonic turbine nozzle vanes," ISROMAC-5 A, pp. 153-169. 